BERICHTE UBBER DIE VERHANDLUNGEN DER SÄCHSISCHEN AKADEMIE DER WISSENSCHAFTEN ZU LEIPZIG

\author{
Philologisch-historische Klasse \\ Band $102 \cdot$ Heft 5
}

WALTE R BAETKE

\title{
ÜBER DIE ENTSTEHUNG DER ISLÄNDERSAGAS
}


Vorgetragen in der Sitzung vom 10. April 1954

Manuskript eingeliefert am 3. November 1955

Druckfertig erklärt am 5. September 1956

Erschienen im Akademie-Verlag GmbH., Berlin W 8, Mohrenstraße 39 Lizenznummer 202 - 100/91/56

Satz und Druck: Druckhaus ,Maxim Gorki“, AItenburg, Bez. Leipzig Bestell- und Verlagsnummer: 2026/102/5

Preis: DM 5,50

Printed in Germany 